\title{
Evaluation and optimization of a circular economy model integrating planting and breeding based on coupling of emergy analysis and life cycle assessment
}

\section{Qingsong Wang}

Shandong University

Yujie Zhang

Shandong University

Shu Tian

Shandong University

Xueliang Yuan ( $\nabla$ yuanxl@sdu.edu.cn )

School of Energy and Power Engineering, Shandong University https://orcid.org/0000-0002-7331-1059

Qiao Ma

Shandong University

Mengyue Liu

Shandong University

Yue Li

Shandong University

Jixiang Liu

Shandong University

\section{Research Article}

Keywords: Circular economy model, Emergy, EM-LCA model evaluation, Optimization

Posted Date: March 9th, 2021

DOI: https://doi.org/10.21203/rs.3.rs-161699/v1

License: (c) (i) This work is licensed under a Creative Commons Attribution 4.0 International License. Read Full License

Version of Record: A version of this preprint was published at Environmental Science and Pollution Research on July 1st, 2021. See the published version at https://doi.org/10.1007/s11356-021-15101-z. 

1 Evaluation and optimization of a circular economy model integrating

2 planting and breeding based on coupling of emergy analysis and life cycle assessment

4 Qingsong Wang ${ }^{1}$, Yujie Zhang ${ }^{1}$, Shu Tian ${ }^{1}$, Xueliang Yuan ${ }^{1, *}$, Qiao Ma ${ }^{1}$, $5 \quad$ Mengyue Liu ${ }^{1}$, Yue Li', Jixiang Liu ${ }^{1}$

${ }^{1}$ National Engineering Laboratory for Reducing Emissions from Coal Combustion, Engineering Research Center of

Environmental Thermal Technology of Ministry of Education, Shandong Key Laboratory of Energy Carbon

Reduction and Resource Utilization, Research Center for Sustainable Development, Jinan, Shandong, 250061,

China

\section{Abstract}

The sustainable development of agriculture is facing problems such as high resource consumption and serious environmental pollution. The development of circular economy model integrating planting and breeding (CEMIPB) has become an effective way to realize the sustainable development of agriculture. However, due to the large regional differences of circular models, references and comparability are generally lacking. Therefore, exploring economic benefit level and sustainability of CEMIPB through an effective evaluation model is necessary. Accordingly, this paper builds a methodological system for model evaluation and optimization based on the EM-LCA model and validates it with a typical CEMIPB in Fujian Province, China. By comparing the results of the EM-LCA and EMA models, the former effectively compensates for the deficiencies of the latter in terms of economic and environmental impact assessment, and the evaluation results can better reflect the actual situation of the system. Furthermore, sensitivity analysis is introduced to identify key processes and substances. Based on the reduce-reuse-recycle principle, several optimization suggestions, such as the corn and veterinary drugs, input reduction are put forward. The construction of the above methodology system can provide a new perspective for research in similar fields and provide a scientific basis for local government decision-making.

Keywords: Circular economy model; Emergy; EM-LCA model evaluation; Optimization

\footnotetext{
* Corresponding author. Tel./fax: +86 531 88395877. E-mail address: yuanxl@sdu.edu.cn (X. Yuan)
} 


\section{Introduction}

As the world's population boomed, agricultural production expanded rapidly. However, such rapid development has caused problems such as resource depletion and environmental degradation (Wesseh and Lin 2017; Iacovidou et al. 2020). As a major agricultural country, China is also facing increasingly prominent resource constraints and environmental problems (Qian et al. 2018; Wang et al. 2018). China is a large country that uses fertilizers and pesticides. The high use and low efficiency of chemical fertilizers and pesticides have resulted in increased input costs and resource consumption. In addition, the huge discharge of agricultural wastes such as straw and livestock manure has caused environmental pollution and ecological damage (Li et al. 2016). Many countries believe that the development of CEMIPB is an important measure to solve these problems (Chen et al. 2010). In accordance with the concept of the circular economy, the CEMIPB uses material recycling technology, transforming the traditional linear production model of "resources-products-discharge" into a circular production model of "resources-products-renewable resources-renewable products" (Wu et al. 2015). The models have obvious natural resource attributes. Owing to the lack of reference and comparability in different types of natural resource regions, combining the attributes of local resources, deeply analyzing which integration model of planting and breeding is suitable for regional development and has a greater level of sustainable development is necessary to provide a reference for local governments in decision-making.

Emergy analysis (EMA) and life cycle assessment (LCA) are two common evaluation methods of circular economy models. In the late 1980s, Odum, a well-known American ecologist, established the theory of EMA by integrating the principles of system ecology, energy ecology, and ecological economy and pointed out that solar energy is the only and most fundamental energy source of biosphere (Odum 1996). Since then, the theory of emergy has provided a scientific method combining ecology and economics and has become an important means to evaluate the value of natural resources and social economy (Pan et al. 2019). Wu et al. (2015) evaluated a CEMIPB in northwest China by using emergy, and the results showed that the circular economy model was more conducive to improving resource utilization efficiency and reducing local environmental pressure than the traditional model. Luo et al. (2017) used emergy to analyze the CEMIPB in Changting, Fujian Province, and proposed ways to improve the CEMIPB. LCA is an assessment method for resource and environmental impact analysis of products and their packaging, production processes, raw materials, energy, or other human activities in the entire process. LCA has become an important decision-making tool for environmental management and product design worldwide and has been gradually applied to ecological industry or circular economy development and clean production (ISO 2006). Zhang et al. (2015) assessed the 
CEMIPB with LCA and proposed corresponding energy saving and emission reduction recommendations using scenario analysis. Fan et al. (2018) used LCA to analyze the CEMIPB with different industrial chain lengths in Fujian Province and pointed out that the best ecological and economic benefits can only be achieved by a reasonable plan for the length of the integration of planting and breeding industrial chain. In summary, EMA and LCA, as mature theoretical and methodological systems, have been highly recognized by scholars in the evaluation of CEMIPB.

However, the current assessment of CEMIPB mainly focuses on a single evaluation method using emergy or LCA. EMA method pays minimal attention to systematic waste absorption and reduction of environmental pollution emission, whereas LCA ignores "free" resources (such as sunlight, wind energy) provided by the natural environment, resulting in some differences in the direction of the evaluation results between the above two methods (Wang et al. 2020). The advantages of the two evaluation methods are complementary (Cui et al. 2018; Duan et al. 2011). Many scholars have conducted in-depth studies on the coupling of EMA and LCA, and these results can be divided into the following three categories. The first category involves separate EMA and LCA evaluations of the target system, followed by a comprehensive or comparative analysis. Wilfart et al. (2013) evaluated three different aquaculture models in France by EMA and LCA and pointed out the economic benefits and environmental performance of each model. The advantage of this approach is comprehensive and detailed, whereas the disadvantage is that the evaluation is too discrete and does not result in holistic indicators. The second category is the refinement of the EMA framework using LCA structures, metrics, or data lists. Brown et al. (2012) referred to the widely used process input standard classification method in LCA and discussed spatial scale, boundary conditions, and input classification schemes that should be applied in EMA. The advantage of this method is that it enhances the consistency and comparability of the evaluation process, whereas the disadvantage is that environmental impacts are not considered. The third type is to form perspectives complementary to EMA and LCA and combine the two into a hybrid model. Wang et al. (2015) evaluated the sustainability of a large-scale pig breeding system in northern China by incorporating the emergy of ecological services needed to dilute pollutants into the emergy evaluation system. The advantage of this method is to convert the environmental impact into a unit unified with emergy, but the disadvantage is that the damage impact of pollutants is not included in the evaluation system. In addition, some scholars proposed to integrate the damage effects of life cycle pollutant emissions into emergy assessment (Jiang et al. 2019; Reza et al. 2014). Although this method can use LCA to quantify the environmental impact of pollutants from two aspects of ecological services and emergy equivalent loss, which is a great improvement compared with the traditional EMA, it can not fully evaluate the characteristics due to the multi-level recycling of wastes in the CEMIPB. 
Based on the above analysis, although coupling EMA and LCA can have the advantages of the two evaluation methods at the same time, the coupling methods are diverse, and different coupling methods have their own advantages and disadvantages, which should not be directly applied to CEMIPB. Therefore, on the basis of literature research, this paper constructs a complete methodology system suitable for the CEMIPB.

\section{Methodology}

Firstly, based on the literature review and the characteristics of the CEMIPB, the EM-LCA model suitable for the evaluation of the CEMIPB is constructed. Based on the traditional EMA, LCA method was used to integrate ecological services and emergy equivalent loss into the emergy evaluation system (Reza et al. 2014). Meanwhile, according to the characteristics of multi-level utilization of waste, the comprehensive utilization efficiency (CUE) indicator is proposed to comprehensively evaluate the waste utilization efficiency. In addition, because the traditional emergy only considers the emery exchange ratio of the output $\left(E E R_{Y}\right)$, the impact of input-output on the economic efficiency of the system couldn't be measured. Therefore, emergy exchange ratio of input $\left(\mathrm{EER}_{\mathrm{I}}\right)$ (Lu et al. 2009) is introduced to improve the economic performance in the traditional emergy index of sustainable development (EISD) indicator. The above three impact values are all converted into emergy, and integrated into the comprehensive evaluation system. Secondly, This paper compares the evaluation results of the improved Em-LCA model and the EMA model to verify the robustness and reliability of the constructed model. Finally, this paper identifies the key substances that restrict the sustainability of the system through sensitivity analysis, and proposes optimization measures and guidelines to improve the sustainability of the system, combined with the "reduce-reuse-recycle" (3R) principle of circular economy and the position of key substances in the system The specific technical route is shown in Fig. 1.

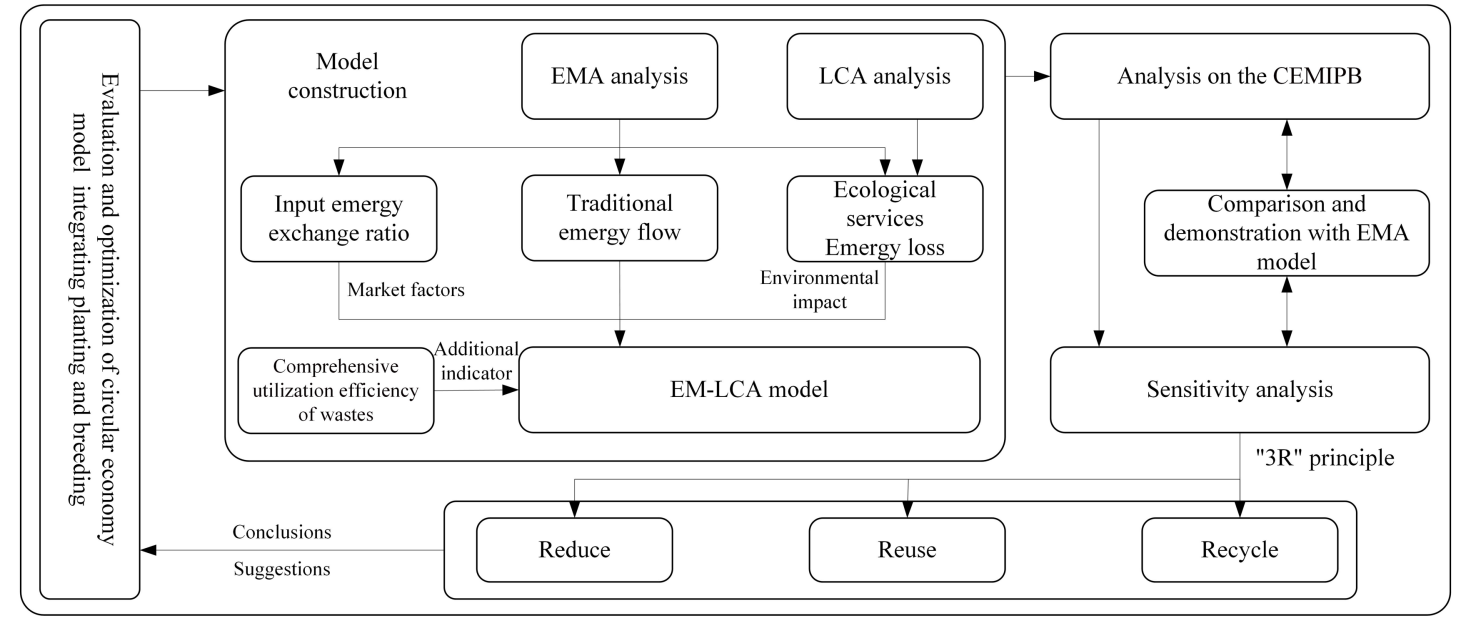

Fig. 1 Roadmap of research methodology for CEMIPB 
Fujian Province, located in the southeast coast of China, has rich natural resources and an excellent ecological environment, providing a good foundation for the development of modern circular agriculture. The Fujian Provincial Government attaches considerable importance to the development of high-efficiency ecological agriculture, leading in proposing the concept of ecological province construction in China and becoming a pilot province for such construction.

128 Modern integration models of planting and breeding have been practiced and explored for more than ten years in Fujian Province, and some achievements have been made.

130 The paper uses a typical CEMIPB in this area as the research object and conducts empirical analysis on it. The target system is divided into farmland planting, large-scale dairy farming, and agricultural wastes comprehensive utilization subsystems with a complete production year as the boundary, as shown in Fig. 2. The total cultivated area is approximately 40 hectares, mainly planted silage corn and alfalfa. All the crops, including straw, are used as roughage for dairy cattle breeding, but some silage corn and alfalfa still need to be purchased. A total of 221 adult cows and 95 calves are at the plant, and the milk produced is sold directly to the public. In addition, a 1,100 $\mathrm{m}^{3}$ biogas digester and an organic fertilizer processing plant are built in the plant area to process agricultural wastes such as manure, food residues, and crop residues. The biogas residue and biogas slurry are transported to the planting system as fertilizer to replenish soil fertility. The biogas generated is used for power generation and supply to the planting system and breeding system. The surplus power is transmitted to nearby enterprises and communities through the power grid, forming a model with multi-level utilization of materials and resource utilization of wastes.

The data sources of this paper are diverse: The enterprise data are obtained by field investigation; The meteorological data, such as wind speed and precipitation, are from China

146 Meteorological Data Network (CMDC 2020). The obtained data are analyzed and checked to 147 ensure the reliability of the research results and reduce the uncertainty. 


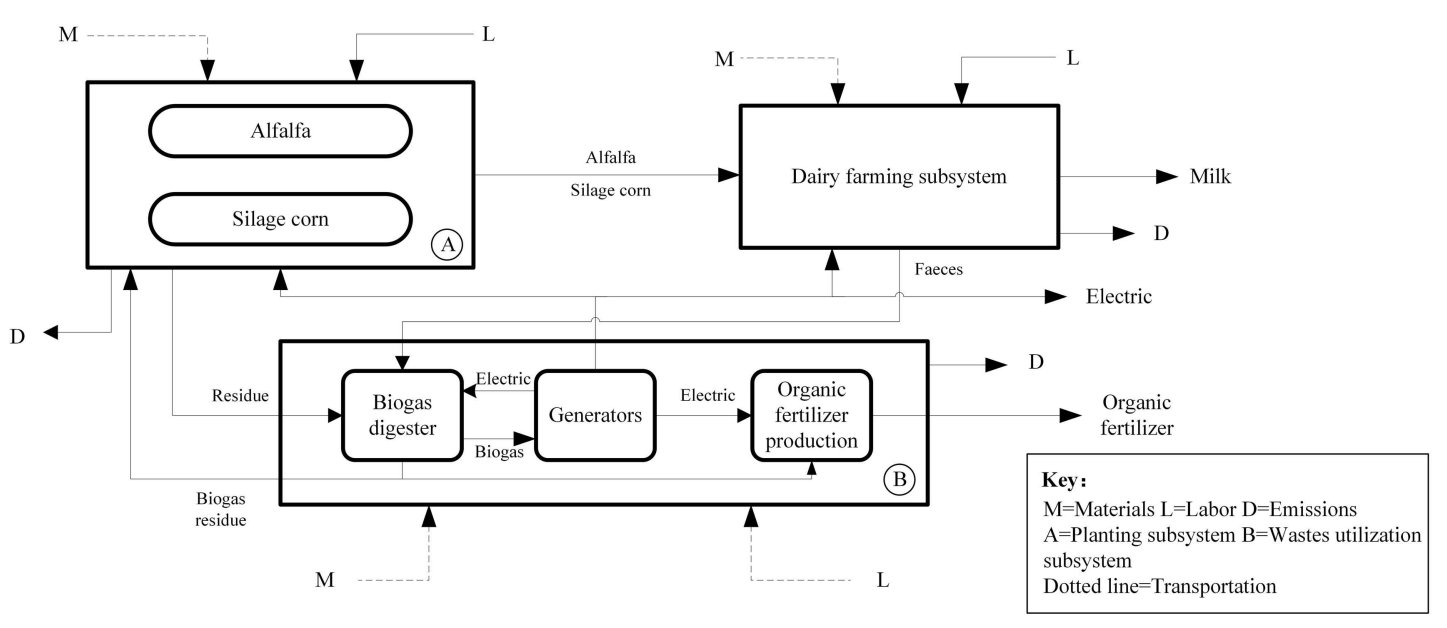

Fig. 2 Flow chart of the CEMIPB

\section{Construction of the EM-LCA coupling indicators system}

Emergy is defined as the total amount of solar energy directly or indirectly required to produce a product or service (Odum, 1996). Emergy can convert different types of resources, energy, and social labor into a unified unit (sej) through unit emergy value (UEV). The calculation method is shown in Eq. (1).

$$
E_{\mathrm{m}}=\sum_{i=1}^{n} E_{\mathrm{mi}}=\sum_{i=1}^{n} f_{i} \times U E V_{i}
$$

where i represents a specific type of material flow or energy flow in the target system. $E_{\mathrm{mi}}$ is the emergy value corresponding to a specific material flow or energy flow. $f_{i}$ is the amount of a specific material flow or energy flow, and its unit is kilogram $(\mathrm{kg})$ or currency $(\$)$. $\mathrm{UEV}_{\mathrm{i}}$ is the unit emergy value, which represents the emergy quantity corresponding to the unit material flow or energy flow, and the unit is sej/unit (such as sej/kg; sej/\$).

The emergy input or output of the system is usually divided into local renewable emergy (R), local non-renewable emergy $(\mathrm{N})$, and purchased emergy $(\mathrm{F})$ depending on different sources and functions. For the purchased emergy, to accurately calculate the renewable emergy content contained in each input, renewable factor (RNF) is introduced to divide F into renewable part (FR) and non-renewable part (FN) (Wilfart et al., 2013; Zhang et al., 2012a). EYR, ELR, EER, ESI, and EISD are explained in Table 1.

Table 1 EMA and EM-LCA comprehensive indicators system construction and comparative analysis

\begin{tabular}{llll}
\hline EM-LCA & EMA & Unit & Interpretation of indicators \\
\hline $\mathrm{R}$ & $\mathrm{R}$ & sej & Local renewable emergy \\
$\mathrm{N}$ & $\mathrm{N}$ & sej & Local non-renewable emergy
\end{tabular}




\begin{tabular}{|c|c|c|c|}
\hline $\mathrm{F}$ & $\mathrm{F}$ & sej & Purchased emergy \\
\hline FR & FR & sej & Renewable part of purchased emergy \\
\hline $\mathrm{FN}$ & $\mathrm{FN}$ & sej & Non-renewable part of purchased emergy \\
\hline Y & $\mathrm{Y}$ & sej & Output emergy \\
\hline K & - & sej & $\begin{array}{l}\text { The part of the emergy output that is fed back to } \\
\text { the system }\end{array}$ \\
\hline Ym & - & sej & $\begin{array}{l}\text { The part of the emergy output of the waste } \\
\text { utilization system that flows into the market }\end{array}$ \\
\hline $\mathrm{ES}_{\text {air }}$ & - & sej & Emergy of ecological services of air \\
\hline $\mathrm{ES}_{\text {water }}$ & - & sej & Emergy of ecological services of water \\
\hline ES & - & sej & Emergy of ecological services \\
\hline EL & - & sej & Emergy equivalent loss \\
\hline $\mathrm{Em} / \$$ & $\mathrm{Em} / \$$ & sej/\$ & $\begin{array}{l}\text { Emergy currency ratio, that is the emergy value } \\
\text { of each currency }\end{array}$ \\
\hline EcI & EcI & $\$$ & Economic cost \\
\hline $\mathrm{EcY}$ & $\mathrm{EcY}$ & $\$$ & Economic income \\
\hline $\mathrm{EYR}=\mathrm{Y} /(\mathrm{F}+\mathrm{ES}+\mathrm{EL})$ & $\mathrm{EYR}=\mathrm{Y} / \mathrm{F}$ & - & Emergy yield ratio \\
\hline $\mathrm{ELR}=\left(\mathrm{FN}+\mathrm{N}+\mathrm{ES}_{\mathrm{water}}+\right.$ & $\mathrm{ELR}=(\mathrm{FN}+\mathrm{N}) /(\mathrm{FR}+$ & - & Emergy loading ratio \\
\hline $\mathrm{EL}) /\left(\mathrm{FR}+\mathrm{R}+\mathrm{ES}_{\text {air }}\right)$ & $\mathrm{R})$ & & \\
\hline $\mathrm{EER}_{\mathrm{Y}}=(\mathrm{EcY} \times \mathrm{Em} / \$) / \mathrm{Y}$ & $\begin{array}{l}\mathrm{EERY}=(\mathrm{EcY} \times \mathrm{Em} / \$ \\
) / \mathrm{Y}\end{array}$ & - & Output emergy exchange ratio \\
\hline $\mathrm{EER}_{\mathrm{I}}=\mathrm{F} /(\mathrm{EcI} \times \mathrm{Em} / \$)$ & - & - & Input emergy exchange ratio \\
\hline $\mathrm{CUE}=\mathrm{K} /(\mathrm{F}+\mathrm{K})+\mathrm{Ym} / \mathrm{Y}$ & - & - & Comprehensive utilization efficiency of wastes \\
\hline $\mathrm{ESI}=\mathrm{EYR} / \mathrm{ELR}$ & $\mathrm{ESI}=\mathrm{EYR} / \mathrm{ELR}$ & - & Emergy sustainability index \\
\hline $\mathrm{EISD}=\mathrm{EER}_{\mathrm{I}} \times \mathrm{EER}_{\mathrm{Y}} \times \mathrm{E}$ & $\mathrm{EISD}=\mathrm{EER}_{\mathrm{Y}} \times \mathrm{EYR} /$ & - & Emergy index of sustainable development \\
\hline YR/ELR & ELR & & \\
\hline
\end{tabular}

\section{Impact assessment of pollutant emission}

172 Pollutants discharged from the system will cause irreversible damage to humans and the ecosystem through inhalable particles and eutrophication of water bodies before reaching a stable state (Zhang et al. 2014), and the damage amount can be quantified by energy equivalent loss (EL).

175 Reliance on the ecological services provided by natural ecosystems, the concentrations of 176 pollutants can be diluted to the acceptable concentrations specified in relevant standards, and the 177 amount of required services can be quantified by ecosystem service emergy (ES). 


\section{Quantification of EL}

Pollutant emissions can cause damage to natural ecology, human health, and land occupation (Zhang et al. 2014). Ecological loss, human health damage, and land occupation can be converted into ecological equivalent energy loss $\left(E L_{\mathrm{EQ}}\right)$, human health damage $\left(\mathrm{EL}_{\mathrm{HH}}\right)$, and land occupation loss $\left(\mathrm{EL}_{\mathrm{SW}}\right)$ by using the potential disappearance fraction (PDF), disability-adjusted life year (DALY), and land occupation coefficient (LOC) respectively, as shown in Eqs. (2)-(4).

$$
E L_{E Q}=\sum \mathrm{m}_{\mathrm{i}} \times P D F_{\mathrm{i}} \times E_{\mathrm{bio}}
$$

In Eq. (2), PDF (\%) is the percentage of species loss in a certain area at a certain time. $\mathrm{m}_{\mathrm{i}}$ is the total emission of a pollutant. $E_{b i o}$ is the annual emergy unit allocated to natural capital in the region, and the value of $\mathrm{E}_{\mathrm{bio}}$ is $5.54 \mathrm{E}+08 \mathrm{sej} / \mathrm{year}$ (Reza et al. 2014).

$$
E L_{H H}=\sum m_{i} \times D A L Y_{\mathrm{i}} \times E_{\mathrm{p}}
$$

In Eq. (3), DALY represents the disability-adjusted life year (year/g) per unit of pollutant emission. $m_{i}$ represents the total emissions of a pollutant. $E_{P}$ represents the annual emergy of each population, and the value of $E_{P}$ is $1.73 \mathrm{E}+17 \mathrm{sej} / \mathrm{year} / \mathrm{pop}$ (Reza et al. 2014).

$$
E L_{S W}=\sum m_{i} \times L_{O C} \times E_{L}
$$

In Eq. (4), LoC is the land occupation coefficient (ha/t), $m_{i}$ is the total amount of certain solid waste emissions (t), and $E_{L}$ is the emergy required per unit of land restoration (Zhang et al. 2010).

EL is the comprehensive emergy loss caused by pollutants to natural ecology, human health, and land occupation, as shown in Eq. (5).

$$
E L=W_{H H} \times E L_{H H}+W_{E Q} \times E L_{E Q}+W_{S W} \times E L_{S W}
$$

In Eq. (5), $\mathrm{W}_{\mathrm{HH}}, \mathrm{W}_{\mathrm{EQ}}$, and $\mathrm{W}_{\mathrm{SW}}$ represent the weight values of the three types of damage, and their values are $0.57,0.33$, and 0.10 respectively, by analytic hierarchy process (AHP).

\section{Quantification of ES}

The emergy required by the natural ecosystem to absorb or dilute air pollutants and water pollutants to reach an acceptable state or concentration level is ES. Eq. (6) represents the mass of air/water required to dilute a pollutant.

$M_{\text {air } / \text { water }}=\mathrm{d} \times(W / c)$

$\mathrm{M}_{\mathrm{air} / \mathrm{water}}$ is the mass $(\mathrm{kg})$ of air or water required to dilute a pollutant. $\mathrm{d}$ is the density of air or water. $\mathrm{W}$ is the mass $(\mathrm{kg})$ of a pollutant discharged into the air or water body, and $\mathrm{c}$ is the specified acceptable concentration $\left(\mathrm{kg} / \mathrm{m}^{3}\right)$ of pollutants in the area (SAC 2012; SAC 2017).

Emergy of ecological services of air or water $\left(\mathrm{ES}_{\mathrm{air} / \text { water }}\right)$ can be obtained by multiplying the kinetic energy/chemical energy of air or water body by the corresponding energy conversion rate, 
as shown in Eqs. (7) and (8).

$211 E S_{\text {air }}=\frac{1}{2} \times M_{\text {air }} \times v^{2} \times U E V_{\text {air }}$

$$
E S_{\text {water }}=M_{\text {water }} \times \rho \times U E V_{\text {water }}
$$

$\mathrm{v}$ is the local average wind speed, and $\rho$ is the internal energy conversion coefficient of the water body. $\mathrm{UEV}_{\text {air }}$ is the emergy transformity of air $\left(2.52 \times 10^{3} \mathrm{sej} / \mathrm{J}\right)$, and $\mathrm{UEV}_{\text {water }}$ is the emergy transformity of water $\left(3.05 \times 10^{4} \mathrm{sej} / \mathrm{J}\right)($ Odum 1996).

Eq. (9) represents the total ecological service emergy (ES) required to dilute all pollutants.

$$
E S=\max \left(E S_{\text {air }}\right)+\max \left(E S_{\text {water }}\right)
$$

Max $\left(\mathrm{ES}_{\text {air }}\right)$ and max $\left(\mathrm{ES}_{\text {water }}\right)$ represent the maximum values of $\mathrm{ES}_{\text {air }}$ for each air pollutant and the maximum value of $\mathrm{ES}_{\text {water }}$ for each water pollutant, respectively.

\section{Results}

First, the emergy flow diagram of the CEMIPB is drawn based on Fig. 2, as shown in Fig. 3. Referring to the research results of Odum and Brown (2000), $15.83 \times 10^{24} \mathrm{sej} / \mathrm{yr}$ is used as the emergy baseline to determine the UEV values of each substance under different baselines. According to the input-output data of the system and relevant calculation methods in Section 2, the system emergy analysis table is compiled (Table 2). Second, the LCA method is used to evaluate the CEMIPB. Based on the EL and ES calculation method designed in Section 2.2, the emergy analysis results of pollutants downstream of the system are obtained, as shown in Table 3. According to the data in Tables 2 and 3, the indicators reflecting the economic benefits, environmental load, and sustainability of the integrated system are calculated. The detailed results are shown in Table 4.

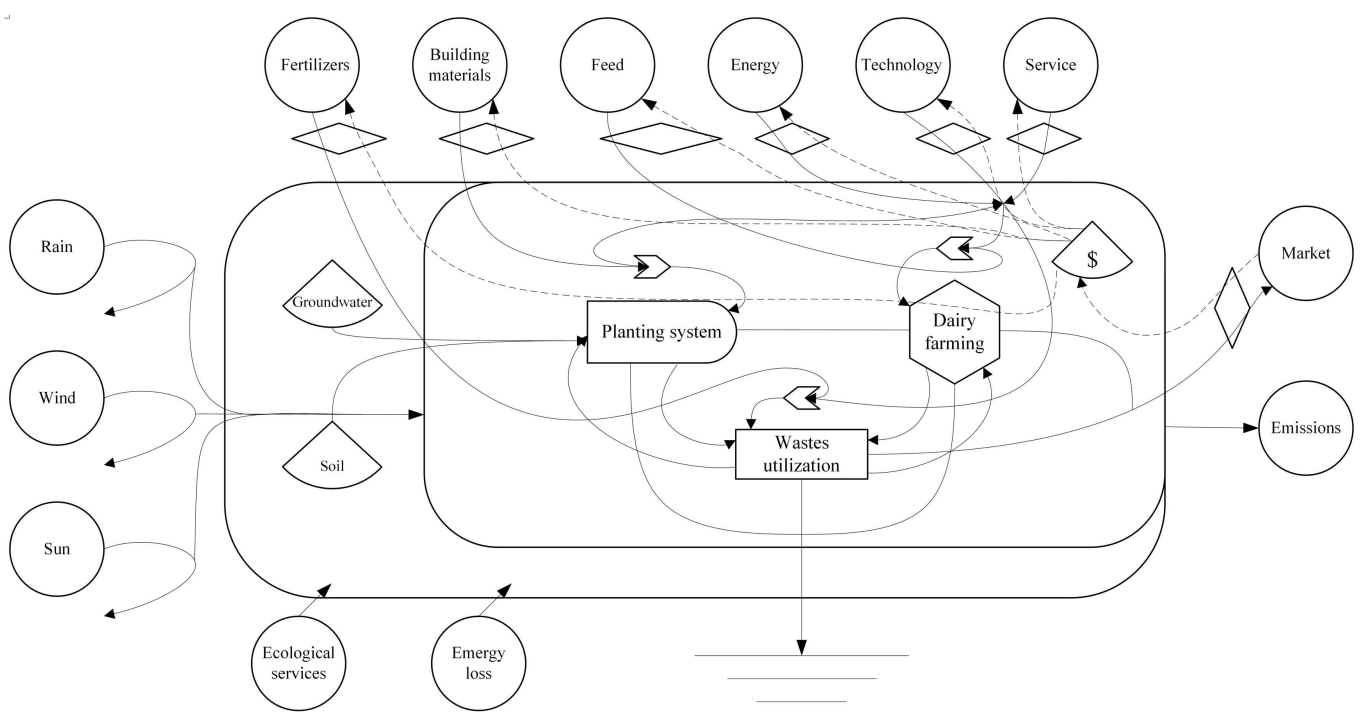

Fig. 3 Emergy flow chart of the CEMIPB 
233 Table 2 Upstream emergy analysis of the CEMIPB

\begin{tabular}{|c|c|c|c|c|c|c|c|c|}
\hline Category & Item & Unit & Data & RNF & UEV (sej/unit) & Reference for UEV & Emergy (sej) & $\begin{array}{l}\text { Import/Sal } \\
\text { price (\$) }\end{array}$ \\
\hline \multicolumn{9}{|c|}{ Local renewable emergy $(\mathrm{R})$} \\
\hline & Sun & $\mathrm{J}$ & $4.90 \mathrm{E}+14$ & 1.00 & $1.00 \mathrm{E}+00$ & & $4.90 \mathrm{E}+14$ & \\
\hline & Rain & $\mathrm{J}$ & $1.14 \mathrm{E}+12$ & 1.00 & $3.10 \mathrm{E}+04$ & Odum(1996) & $3.54 \mathrm{E}+16$ & \\
\hline & Wind & $\mathrm{J}$ & $6.30 \mathrm{E}+11$ & 1.00 & $2.45 \mathrm{E}+03$ & Odum(1996) & $1.54 \mathrm{E}+15$ & \\
\hline \multicolumn{9}{|c|}{ Local non-renewable emergy $(\mathrm{N})$} \\
\hline & Topsoil loss & $\mathrm{J}$ & $1.98 \mathrm{E}+11$ & 0.00 & $1.24 \mathrm{E}+05$ & Brandt-Williams (2002) & $2.45 \mathrm{E}+16$ & \\
\hline & Groundwater & $\mathrm{J}$ & $1.18 \mathrm{E}+10$ & 0.00 & $2.45 \mathrm{E}+05$ & Wang et al. (2015) & $2.89 \mathrm{E}+15$ & \\
\hline \multicolumn{9}{|c|}{ Purchased emergy (F) } \\
\hline Building & rials & & & & & & & \\
\hline & Steel & $\mathrm{g}$ & $1.16 \mathrm{E}+06$ & 0.05 & $1.13 \mathrm{E}+10$ & Brown and Ulgiati (2002) & $1.31 \mathrm{E}+16$ & 7.13E +02 \\
\hline & Brick & g & $1.20 \mathrm{E}+07$ & 0.05 & $2.87 \mathrm{E}+09$ & Odum(1996) & $3.43 \mathrm{E}+16$ & $2.94 \mathrm{E}+02$ \\
\hline & Concrete & $\mathrm{g}$ & $1.73 \mathrm{E}+07$ & 0.05 & $1.68 \mathrm{E}+09$ & Brown and Ulgiati (2002) & $2.91 \mathrm{E}+16$ & $3.20 \mathrm{E}+02$ \\
\hline & Glass & $\mathrm{g}$ & $3.10 \mathrm{E}+05$ & 0.05 & $3.83 \mathrm{E}+07$ & Ulgiati and Brown (2002) & $1.19 \mathrm{E}+13$ & $3.81 \mathrm{E}+01$ \\
\hline \multicolumn{9}{|l|}{ Feed } \\
\hline & Corn & $\mathrm{g}$ & $2.03 \mathrm{E}+08$ & 0.21 & $2.09 \mathrm{E}+09$ & Wu et al. (2013) & $4.22 \mathrm{E}+17$ & $4.98 \mathrm{E}+04$ \\
\hline & Soybean meal & g & $2.03 \mathrm{E}+07$ & 0.21 & $3.32 \mathrm{E}+09$ & Wu et al. (2013) & $6.72 \mathrm{E}+16$ & $6.22 \mathrm{E}+03$ \\
\hline & Wheat bran & g & $5.06 \mathrm{E}+07$ & 0.21 & $3.03 \mathrm{E}+09$ & Wu et al. (2013) & $1.53 \mathrm{E}+17$ & $6.22 \mathrm{E}+03$ \\
\hline
\end{tabular}




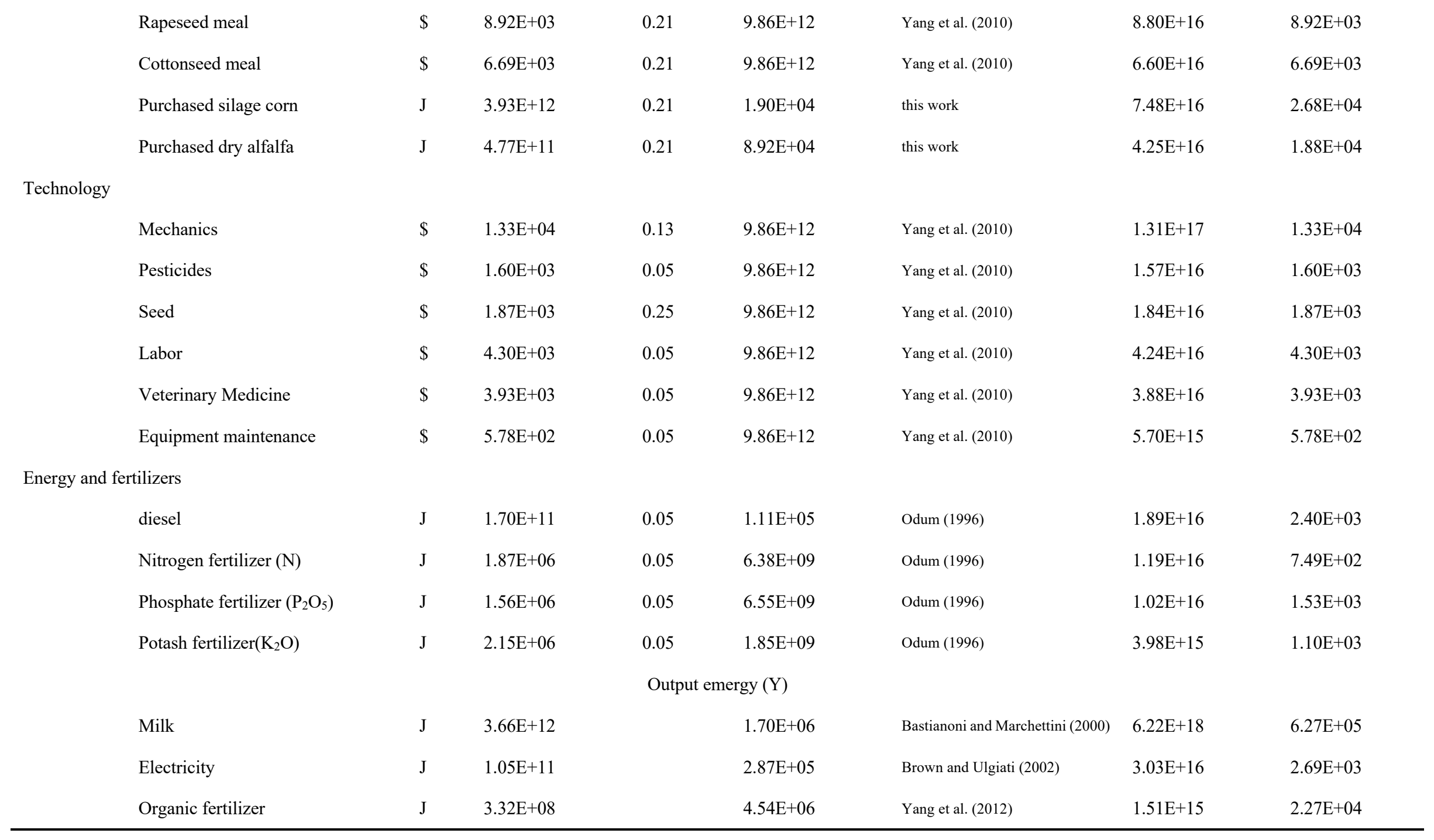


234 Table 3 Downstream emergy analysis of the CEMIPB

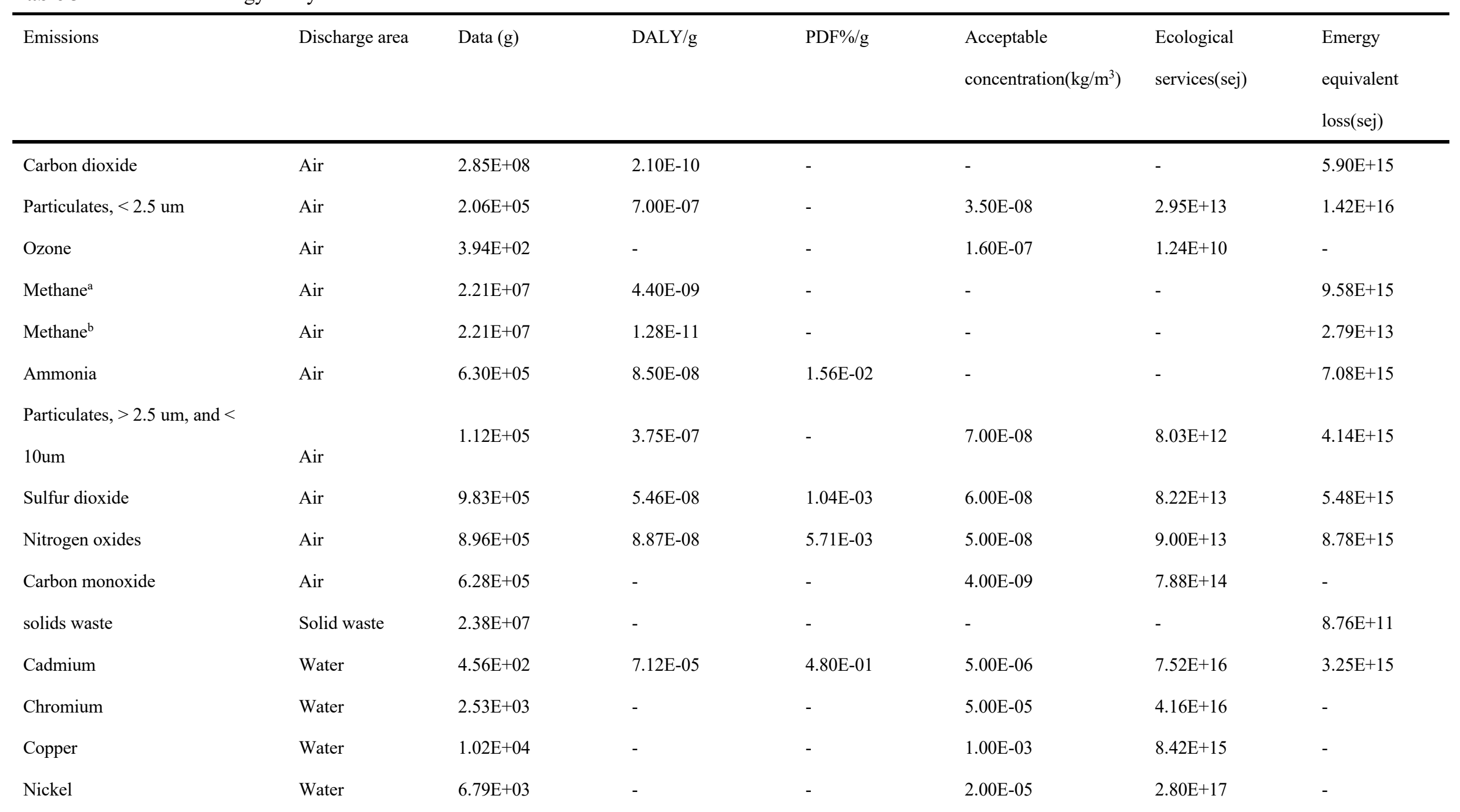




\begin{tabular}{|c|c|c|c|c|c|c|c|}
\hline Zinc & Water & $1.98 \mathrm{E}+04$ & - & - & $1.00 \mathrm{E}-03$ & $1.63 \mathrm{E}+16$ & - \\
\hline Lead & Water & $1.13 \mathrm{E}+03$ & - & 7.39E-03 & $1.00 \mathrm{E}-05$ & $4.61 \mathrm{E}+11$ & $1.53 \mathrm{E}+12$ \\
\hline COD & Water & $9.59 \mathrm{E}+05$ & - & - & 3.00E-03 & $2.63 \mathrm{E}+17$ & - \\
\hline Cyanide & Water & $6.99 \mathrm{E}+01$ & 4.60E-08 & - & $5.00 \mathrm{E}-05$ & $1.15 \mathrm{E}+15$ & $3.17 \mathrm{E}+11$ \\
\hline Mercury & Water & $2.21 \mathrm{E}+01$ & - & - & $1.00 \mathrm{E}-06$ & $1.82 \mathrm{E}+16$ & - \\
\hline Aluminium & Water & $3.20 \mathrm{E}+05$ & - & - & 2.00E-04 & $1.32 \mathrm{E}+18$ & - \\
\hline Arsenic & Water & $1.05 \mathrm{E}+03$ & $6.57 \mathrm{E}-05$ & $1.14 \mathrm{E}-02$ & $1.00 \mathrm{E}-05$ & $4.28 \mathrm{E}+11$ & $6.80 \mathrm{E}+15$ \\
\hline
\end{tabular}


Table 4 Comparative analysis of EM-LCA and EMA indicators results

\begin{tabular}{|c|c|c|c|}
\hline Indicators & Unit & EM-LCA & EMA \\
\hline $\mathrm{R}$ & sej & $3.54 \mathrm{E}+16$ & $3.54 \mathrm{E}+16$ \\
\hline $\mathrm{N}$ & sej & $2.74 \mathrm{E}+16$ & $2.74 \mathrm{E}+16$ \\
\hline $\mathrm{F}$ & sej & $1.29 \mathrm{E}+18$ & $1.29 \mathrm{E}+18$ \\
\hline FR & sej & $2.25 \mathrm{E}+17$ & $2.25 \mathrm{E}+17$ \\
\hline FN & sej & $1.07 \mathrm{E}+18$ & $1.07 \mathrm{E}+18$ \\
\hline Y & sej & $6.25 \mathrm{E}+18$ & $6.25 \mathrm{E}+18$ \\
\hline Ym & sej & $3.18 \mathrm{E}+16$ & - \\
\hline K & sej & $1.18 \mathrm{E}+17$ & - \\
\hline $\mathrm{ES}_{\text {air }}$ & sej & $7.88 \mathrm{E}+14$ & - \\
\hline $\mathrm{ES}_{\text {water }}$ & sej & $2.80 \mathrm{E}+17$ & - \\
\hline EL & sej & $6.52 \mathrm{E}+16$ & - \\
\hline EYR & - & 3.83 & 4.85 \\
\hline ELR & - & 5.51 & 4.20 \\
\hline ESI & - & 0.69 & 1.16 \\
\hline CUE & - & 0.09 & - \\
\hline $\mathrm{EER}_{\mathrm{Y}}$ & - & 1.03 & 1.03 \\
\hline $\mathrm{EER}_{\mathrm{I}}$ & - & 0.84 & - \\
\hline EISD & - & 0.60 & 1.19 \\
\hline
\end{tabular}

\section{Comparative analysis of EYR}

240 EYR is an important indicator to reflect the economic output capacity of a system. The higher 241 the EYR value, the more emergy the system outputs under a specific external emergy input. 242 Therefore, EYR can be used to judge the industrial benefits and competitiveness of the CEMIPB.

243 The EMA model only focuses on social and economic benefits, whereas the EM-LCA model 244 incorporates ecological service benefits. Therefore, theoretically, the EYR value of the former 245 should be higher than that of the latter. As analyzed in Table 4, the EYR indicator (4.85) of the 246 EMA model is $26.84 \%$ higher than that of the EM-LCA model (3.83). The large difference in 247 results indicates that despite agricultural wastes having been used in multiple stages, the 248 environmental cost and emergy damage caused by pollutants remain large, and further work is 249 needed to reduce the total pollutants emissions in the life cycle of the system. However, the values 250 of the two models are higher than the EYR (1.18) of China's agricultural production system in 2512015 (Liu et al., 2019), indicating that the CEMIPB can fully develop local resources and has 
good industrial benefits and competitiveness.

\section{Comparative analysis of ELR}

ELR is an indicator that reflects the degree of environmental impact of a system. The larger the value, the stronger the intensity of the use of non-renewable emergy in the system and the higher the environmental load. According to Brown and Ulgiati (2004), as the ELR rises above 5 for a long time, the system will cause irreversible functional degradation of the environmental system due to excessive stress on the surrounding environment. As analyzed in Table 4, the ELR indicators of the EMA and the EM-LCA model are 4.20 and 5.51, respectively, indicating that the model is highly dependent on non-renewable resources and the system has caused greater environmental pressure on the surroundings. Given that the EMA model does not consider the effect of pollutants downstream of the system on the environment, its value is $23.75 \%$ lower than that of the EM-LCA model, often leading to some cognitive misunderstandings for decision-makers because the EMA model cannot actually reflect the impact of system load on the environment. The EM-LCA model only compensates for the defects of the EMA model in this respect. Consequently, from the perspective of reflecting the environmental load, the EM-LCA model has obvious advantages.

\section{Comparative analysis of EER}

In the EMA model, the output emergy exchange ratio $\left(E E R_{Y}\right)$ is used to evaluate the emergy balance between the two parties in the transaction when the system product is sold (Odum, 1996). However, a comprehensive assessment of the impact of market exchange on the system requires consideration of both emergy exchange ratios of system input and output. Therefore, in the EM-LCA model, the input emergy exchange ratio $\left(\mathrm{EER}_{\mathrm{I}}\right)$ is introduced, which is the emergy exchange rate for the purchase of production materials ( $\mathrm{Lu}$ et al. 2009). A fair transaction should make EER I and EERY equal to 1, that is, both sides reach trade equality. According to Table 4, the $\mathrm{EER}_{\mathrm{I}}$ indicator of the system is 0.80 , which is less than 1 . This finding shows that the emergy equivalent to the currency paid is higher than the actual emergy when purchasing external resources, that is, $16 \%$ of the equivalent emergy of the payment currency is lost in the process of purchasing production materials. For the system output, the EERY indicator is 1.03, which is approximately equal to 1 , indicating that the equivalent emergy value of the currency obtained in the sale of the products is approximately equal to the actual emergy value of the products; that is, both parties in the transaction have reached trade equality, and the market price of milk represents the true value of milk. 
CUE is a creative indicator to evaluate the system wastes recycling capacity, and it is included in the EM-LCA model. The indicator comprehensively evaluates the ability of waste utilization to support the operation of the system from the aspects of reducing input and increasing output. As shown in Table 4, the CUE indicator of the CEMIPB is 0.09, which shows that the sum of the proportion of reduced purchasing emergy and increased output emergy is approximately $9 \%$. It realizes the multi-level utilization of energy and enhances the self-sufficiency of the system, which are conducive to the sustainable development of the system. From the perspective of wastes utilization, this indicator can provide additional valuable information for decision-makers by evaluating the self-organizing ability of the integrated circular models in different natural regions.

\section{Comparative analysis of ESI}

ESI is an indicator that characterizes the sustainability of the system. Generally, when the ESI is greater than 1, the production process of the system is sustainable (Odum 1996). The higher the ESI, the greater the social and economic benefits, and the higher the sustainability level of the system. According to the analysis in Table 4, the ESI indicator of the EM-LCA model is 0.69, and its value is less than 1 , indicating that the sustainability level of the system is low. The ESI indicator of the EMA model is 1.16 , and its value is greater than 1, indicating that the sustainability level of the system is high. The two models come to the opposite conclusion. Given that the EMA model ignores the emergy damage and ecological service benefits caused by pollutants downstream of the system, the results of system sustainability are high and inconsistent with the actual development level of the circular economy model. These findings also show that the downstream ecological services and emergy damage have a considerable impact on the sustainability of the system and cannot be ignored. In addition, the ESI indicator does not reflect the contribution of the currency emergy compensation environment to the system, that is, it does not consider the role of EER. Therefore, introducing EISD indicator for further explanation is necessary.

\section{Comparative analysis of EISD}

EISD is a composite evaluation indicator of the sustainable development performance of the system, which considers the social and economic benefits and the pressure of the ecological environment. The indicator takes the product of emergy output ratio and emergy exchange ratio as

314 a numerator, which can effectively reflect the social and economic benefits of the system. 315 Therefore, using EISD to evaluate the sustainability of the system is a comprehensive approach 316 (Yang et al., 2020). The higher the EISD value, the more sustainable the system. The EISD 
indicator of the EM-LCA model is 0.60 , which is $49.71 \%$ lower than that of the EMA model (1.19). On the one hand, the EMA model only considers the emergy exchange ratio at the output of the system and ignores the emergy exchange ratio at the input of the system, leading to a high result (as seen in Table 4, the $\mathrm{EER}_{\mathrm{I}}$ is less than 1). On the other hand, the EMA model only considers the environmental pressure caused by resource input and ignores the ecological service benefit and equivalent loss of emergy generated downstream of the system, leading to further high evaluation results. The EISD indicator of the EM-LCA model makes up for the shortcomings of the EMA model, and its evaluation results can better reflect the actual sustainable development level of the system. Therefore, the EM-LCA model has greater advantages compared with the traditional EMA model.

\section{Optimization discussion}

\section{Key emergy flow identification}

According to the above results, although the CEMIPB has realized the multi-level utilization of agricultural wastes, the sustainability of the system is low, and potential for further optimization remains. The emergy flow input to the upstream of the system can be divided into three types, namely, local renewable emergy flow (R), local non-renewable emergy flow $(\mathrm{N})$, and purchased emergy flow (F). By quantifying the share of the above three types of emergy flows in the total emergy input, the key emergy flows, i.e., those with a large proportion of weight, are identified. As analyzed in Table 2, the proportion of purchasing emergy flow in EMA and EM-LCA model is much higher than that of the remaining main emergy flows, accounting for $95.3 \%$ and $75.9 \%$, respectively. Thus, the purchasing emergy flow is the key emergy flow that affects the level of sustainability development level of the system. To further analyze the critical substances that are the key substances affecting the sustainable development of the system in the purchasing emergy flow, sensitivity analysis is introduced for further analysis and discussion.

\section{Sensitivity analysis}

Sensitivity analysis is a method that reflects the change degree of relevant indicators through changes in input data. Sensitivity analysis is used to diagnose and identify critical substances in the system with reference to ISO14040 (2006) (Eq. (10)).

$S C=\left|\frac{\left(E E_{2}-E E_{1}\right) / E E_{1}}{\left(C_{2}-C_{1}\right) / C_{1}}\right|$

$\mathrm{SC}$ is the sensitivity coefficient, $\mathrm{C}_{1}$ and $\mathrm{C}_{2}$ are the values before and after the change of main parameters, and $\mathrm{EE}_{1}$ and $\mathrm{EE}_{2}$ are the corresponding indicator values before and after the change of 

analysis results are shown in Table 5 and Figs. 4 and 5.

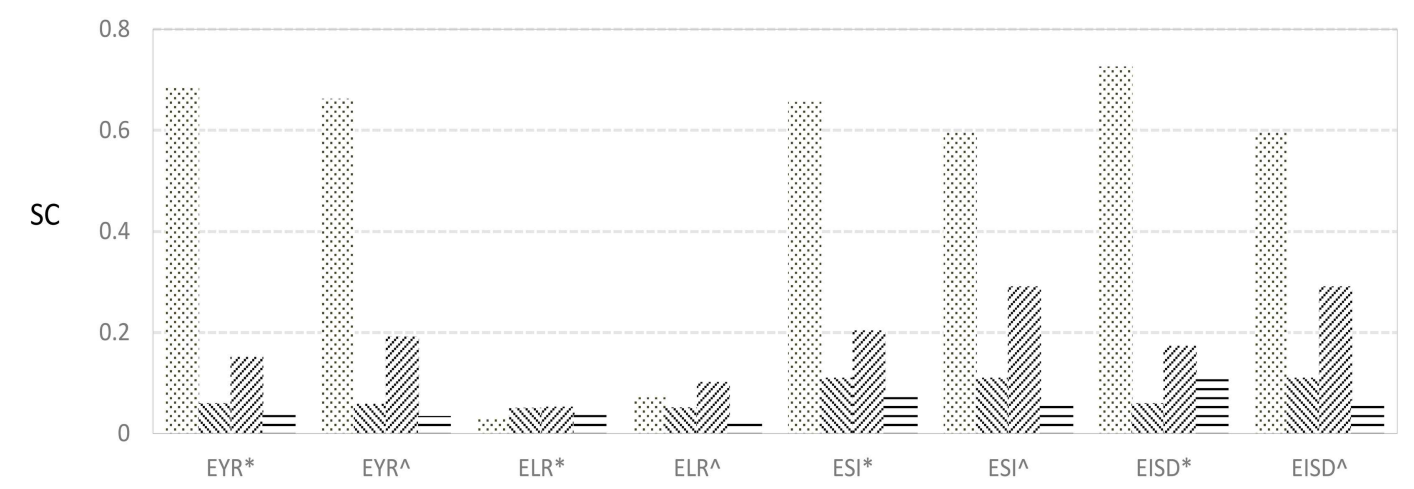

351 Fig. 4 Impact of 10\% emergy flow increase on key indicators (* represents the EM-LCA model; ^ represents the EMA model)

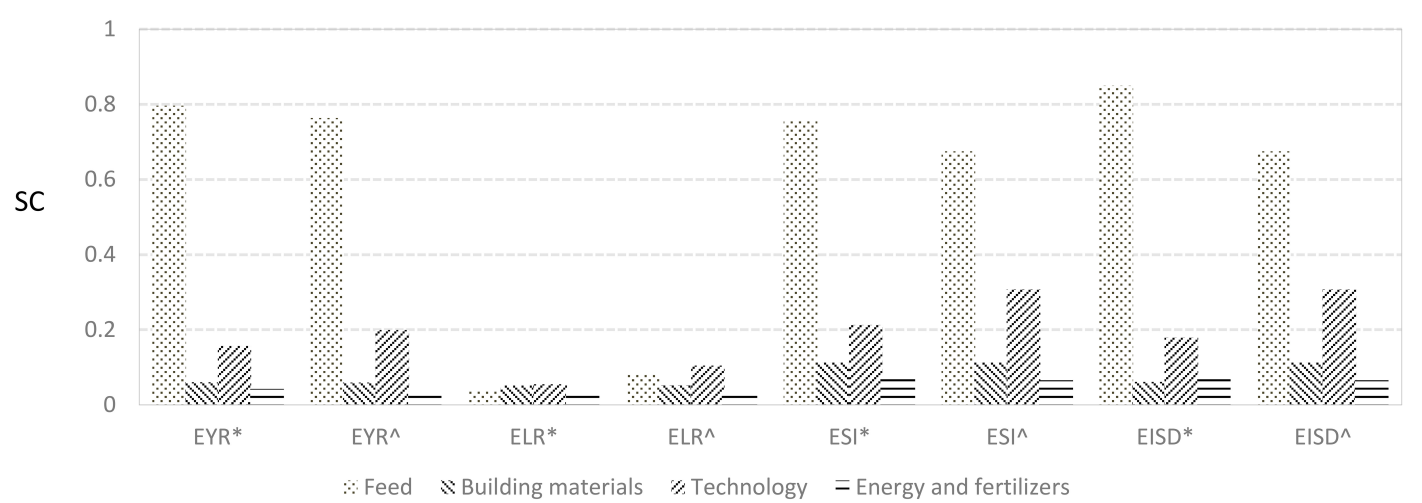

Fig. 5 Impact of 10\% emergy flow decrease on key indicators (* represents the EM-LCA model; ^ represents the EMA model) 
358 Table 5 Impact of emergy flow on key indicators after increasing and decreasing by $10 \%$

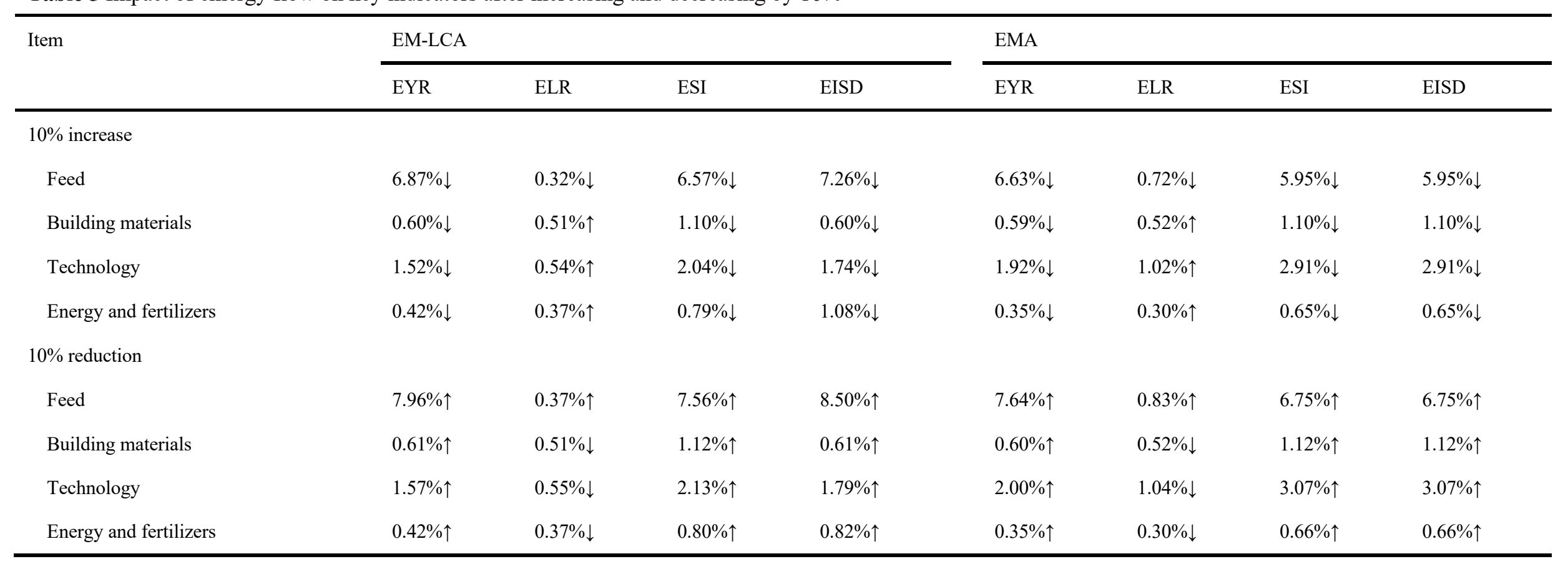


The analysis of Figs. 4 and 5 indicates that the main indicators of the CEMIPB have varying degrees of sensitivity to the four categories of purchasing emergy. The classification of purchasing emergy is shown in Table 3. According to the analysis in Table 5, when the emergy flow of feed, technology, energy and fertilizers, and building materials increase by $10 \%$, the EISD indicator of the EM-LCA model is decreased by $7.26 \%, 1.74 \%, 1.08 \%$, and $0.60 \%$, respectively, and the EISD indicator of the EMA model is decreased by $5.95 \%, 2.91 \%, 0.65 \%$, and $1.10 \%$, respectively. The overall sensitivity of the EM-LCA model is similar to the EMA model, but the sensitivity of the EM-LCA model to feed, energy, and fertilizers is slightly higher, and that of the EMA model for technology and building materials is slightly higher. The reason is that when a given material flow changes, the emergy consumption (emergy input) and the emergy loss caused by indirect emissions (emissions from extraction, production, and transportation) change at the same time, but their change ranges are not the same. The EMA model only considers the change in emergy consumption, whereas the EM-LCA model also considers the changes in both and considers the influence factors of the input market transaction. Therefore, the EM-LCA model can reflect the real sensitivity of the materials and is more conducive to identifying the key substances restricting the sustainable development of the system. The purpose of adopting agricultural circular economy system is to promote regional sustainable development. Therefore, EISD is used as the key indicator to analyze the sensitivity of the input changes of four types of purchasing emergy flow to it, and the sensitivity results in turn are feed $>$ technology $>$ energy and fertilizers $>$ building materials.

380 The above analysis indicates that feed emergy flow and technology emergy flow are two highly sensitive emergy flows, with corn having the highest share. According to Eq. (10), when corn increases by $10 \%$, EYR, ELR, ESI, and EISD in the EM-LCA model are decreased by $3.42 \%$, $0.01 \%, 3.41 \%$, and $3.32 \%$, respectively, whereas EYR, ELR, ESI, and EISD in the EMA model are decreased by $3.18 \%, 0.34 \%, 2.84 \%$, and $2.84 \%$, respectively. By analogy, the sensitivity of each material flow in feed and technology can be analyzed, and the order of material sensitivity is as follows: corn $>$ labor force $>$ veterinary drugs $>$ others. Therefore, corn, labor force, and veterinary drugs are the key substances that restrict the sustainable development of the CEMIPB.

\section{Optimization suggestions}

Based on the above analysis, according to the position of key substances in the system and combined with the " $3 \mathrm{R}$ " principle, the following optimization scenario suggestions are proposed.

Scenario I: how can the source reduction of corn feed input be realized? One effective way is to improve the total yield of corn by optimizing the way that corn is grown. Gou (2017) suggested that corn and wheat had the advantage of intercropping, and the yield of corn was $49 \%$ higher than maize alone if sown together. Zhang et al. (2012b) suggested that maize soybean intercropping 
could significantly increase the content of protein, oil, and lysine in grain and improve the enzyme activity in soil. In addition, Zhao (2020) concluded that grinding the harvested corn cob into corn cob powder and adding it into corn feed could effectively reduce the amount of corn input, and the crude fiber in the corn cob was conducive to the normal activity of the digestive tract function of cows. According to the case analysis in the paper, mixing corn cob meal in corn feed can reduce corn demand by $12.5 \%$. In the EM-LCA model, the indicators EYR and EISD are increased by $4.86 \%$ and $37.32 \%$, and ELR is reduced by $23.73 \%$. Therefore, the above measures can effectively improve crop yield and feed quality, reducing the feed input of breeding system and improving the intensive utilization rate of local land.

Scenario II: how can the cost of labor and veterinary drugs be effectively reduced? The application of Internet-of-Things (IoT) technology to breeding subsystem can greatly reduce labor costs and improve work efficiency (Yuan 2019). The automatic management of dairy farming realizes the automatic feeding and milking of dairy cows, reducing the cost of labor and dairy farming, and tracing the source of each cow. In addition, the reduction of veterinary drugs can be achieved by optimizing the production mode. Qin (2019) believed that strengthening the feeding management in the perinatal period is an important measure to improve the immunity of dairy cows and reduce the use of veterinary drugs. Such feeding management includes the selection of dairy feed, the preparation of diet, feeding methods, and daily management. Therefore, introducing IoT technology and improving its feed structure can effectively reduce labor and veterinary drug costs.

Scenario III: Although the sensitivity of energy and fertilizers is not very high, the reason for this finding is that the feedback materials generated by the recycling of wastes replace a large proportion of energy and chemical fertilizers, resulting in low sensitivity of energy and fertilizers. Therefore, it is necessary to take corresponding measures to further enhance recycling efficiency. Based on the case study, the wastes utilization subsystem can be operated at full capacity by purchasing agricultural wastes such as straw and manure nearby, and the planting scale of alfalfa and silage corn should be expanded to fully use feedback materials. The results show that EYR and EISD in EM-LCA model are increased by $2.66 \%$ and $46.36 \%$, respectively, while ELR is reduced by $10.48 \%$, optimizing the effect of wastes recycling. Therefore, by combining the actual situation of the system and adopting the above approaches, the economy and sustainable development capability of the system will be further improved.

\section{Conclusions}

The main contribution of this paper is to construct a methodology system for the evaluation and 
optimization of the CEMIPB based on the EM-LCA model and the "3R" principle. Compared with the traditional EMA model, the EM-LCA takes the ecological service emergy and emergy loss into the indicators system and considers the impact of the input-output market transactions on system sustainability. The construction of these indicators and methods enables EM-LCA model to evaluate and compare the same system with the EMA model in a quantitative way.

Through the comparative analysis of key indicators, the EM-LCA model not only considers the ecological service benefits of the downstream system but also considers the emergy equivalent loss caused by pollutant emissions. Therefore, compared with the EMA, its value can reflect the actual impact of the system on the surrounding environment. In addition, the sensitivity analysis of the two models to the same system shows that the sensitivity of the EMA model and EM-LCA models to the main emergy flows of the system are similar, but the sensitivity of specific given emergy flow is different. The reason is that the EMA model only considers the impact of changes in emergy flow on emergy consumption, whereas the EM-LCA model also considers the impact of changes in emergy flow on environmental emissions and import market trade. Therefore, the EM-LCA model has higher reliability, and its evaluation results are relatively more accurate with a lower degree of uncertainty.

The key material obtained by sensitivity analysis is an important object of system optimization. Based on the position of key substances in the system, this paper puts forward some optimization suggestions according to the "3R" principle, which provides the direction for the continuous improvement of the system. The construction of this methodological system can provide a new perspective for research in similar fields. An increasing number of experts and scholars are expected to pay more attention to this methodological system and continue to enrich and improve it.

Authors' contributions Qingsong Wang: Investigation, Conceptualization, Methodology, Data curation, Formal analysis, Writing - original draft, Visualization, Writing - review \& editing. Yujie Zhang: Visualization, Writing - review \& editing. Shu Tian: Conceptualization, Methodology, Data curation, Formal analysis, Writing - review \& editing. Xueliang Yuan: Data curation, Visualization. Qiao Ma: Conceptualization, Methodology. Mengyue Liu: Investigation. Yue Li and Jixiang Liu: Investigation. 
Data availability The datasets used and/or analysed during the current study are available from the corresponding author on reasonable request.

464

465

466

467

468

469

470

471

472

473

474

475

476

477

478

479

480

481

482

483

484

485

486

487

488

489

490

491

492

\section{Compliance with ethical standards}

Competing interests The authors declare that they have no known competing financial interests or personal relationships that could have appeared to influence the work reported in this paper.

Ethical approval and consent to participate Not applicable.

Consent to publish Not applicable.

\section{References}

Bastianoni S, Marchettini, N (2000) The problem of co-production in environmental accounti ng by energy analysis. Ecol Model 129:187-193. https://doi.org/10.1016/S0304-3800(00)00 $\underline{232-5}$

Brandt-Williams SL (2002) Emergy of Flodida Agficulture. Folio \#4. Handbook of Emergy Evaluation, Center for Environmental Policy, University of Florida, Gainesville, USA

Brown MT, Raugei M, Ulgiati S (2012) On boundaries and 'investments' in Emergy Synthesi S and LCA: A case study on thermal vs. photovoltaic electricity. Ecol Indic 15:227-235. $\underline{\mathrm{h}}$ ttps://doi.org/10.1016/j.ecolind.2011.09.021

Brown MT, Ulgiati S (2002) Emergy evaluations and environmental loading of electricity pro duction systems. J Clean Prod 10:321-334. https://doi.org/10.1016/S0959-6526(01)00043-9

Brown MT, Ulgiati, S (2004) Energy quality, emergy, and transformity: H.T. Odum's contributions to quantifying and understanding systems. Ecol Model 178:201-213. https://doi.org/10.1016/j.ecolmodel.2004.03.002

Chen M, Chen J, Sun F (2010) Estimating nutrient releases from agriculture in China: An extended substance flow analysis framework and a modeling tool. Sci Total Environ. 408:5123-5136. https://doi.org/10.1016/j.scitotenv.2010.07.030.

CMDC (China Meteorological Data Service Center) (2020) http://data.cma.cn/en. Accessed 28 October 2020

Cui J, Yan P, Wang X, Yang J, Li Z, Yang X, Sui P Chen Y (2018) Integrated assessment of economic and environmental consequences of shifting cropping system from wheat-maize to monocropped maize in the North China Plain. J Clean Prod 193: 524-532. 
10.1016/j.jclepro.2018.05.104

Duan N, Liu XD, Dai J, Lin C, Xia XH, Gao RY, Wang Y, Chen SQ, Yang J, Qi J (2011) Evaluating the environmental impacts of an urban wetland park based on emergy accounting and life cycle assessment: A case study in Beijing. Ecol Model 222:351-359. https://doi.org/10.1016/j.ecolmodel.2010.08.028.

Fan WG, Dong XB, Wei HJ, Weng BQ, Liang L, Xu Z, Wang XC, Wu FL, Chen ZD, Jin Y, Song CQ (2018) Is it true that the longer the extended industrial chain, the better the circular agriculture? A case study of circular agriculture industry company in Fuqing, Fujian. J Clean Prod 189:718-728. https://doi.org/10.1016/j.jclepro.2018.04.119.

Gou F, Yin W, Hong Y, van der Werf W, Chai Q, Heerink N, van Ittersum MK (2017) On yield gaps and yield gains in intercropping: Opportunities for increasing grain production in northwest China. Agric Syst 151:96-105. https://doi.org/10.1016/j.agsy.2016.11.009.

Iacovidou E, Hahladakis JN and Purnell P (2020) A systems thinking approach to underst anding the challenges of achieving the circular economy. Environ Sci Pollut Res https:/ /doi.org/10.1007/s11356-020-11725-9

ISO 14040 (2006) Environmental Management-life Cycle Assessment-principles and Framewo rk. International Standard. http://www.iso.org/iso/home/store/catalogue tc/catalogue detail.h $\underline{\text { tm? csnumber }=37456 .}$ Accessed 28 October 2020

Jiang, Q, Liu, Z., Li, T, Cong, W and Zhang, H (2019) Emergy-based life-cycle assessme nt (Em-LCA) for sustainability assessment: a case study of laser additive manufacturing versus CNC machining. Int J Adv Manuf Technol 102:4109-4120. https://doi.org/10.10 $\underline{07 / \mathrm{s} 00170-019-03486-8}$

Li F, Cheng SK, Yu HL, Yang, DW (2016) Waste from livestock and poultry breeding and its potential assessment of biogas energy in rural China. J Clean Prod 126:451-460. https://doi.org/10.1016/j.jclepro.2016.02.104.

Liu ZX, Wang YY, Geng YL, Li RD, Dong HJ, Xue B, Yang TH, Wang SS, (2019) Toward sustainable crop production in China: An emergy-based evaluation. J Clean Prod 206:11-26. https://doi.org/10.1016/i.jclepro.2018.09.183.

Lu HF, Kang WL, Campbell DE, Ren H, Tan YW, Feng RX, Luo JT Chen FP (2009) Emer gy and economic evaluations of four fruit production systems on reclaimed wetlands surro unding the Pearl River Estuary. China Ecol Eng 35:1743-1757. https://doi.org/10.1016/j.ec oleng.2009.08.001.

Luo XH, Huang Y, Fang YY, Chen E, Yang YQ Weng BQ (2017) Emergy-value analysis on pattern of circular agriculture industry alliance in Changting County. Sci Soil Water Conserv 15:117-126 (In Chinese). 
Odum HT (1996) Environmental Accounting: Emergy and Environmental Decision Making. John Wiley \& Sons, New York.

Odum HT, Brown M (2000) Handbook of emergy evaluation. Center for Environmental Policy. Elsevier, New York.

Pan H, Geng Y, Tian X, Wilson J, Chen W, Zhong S, Song X (2019) Emergy-based environmental accounting of one mining system. Environ Sci Pollut Res 26:14598-14615. https://doi.org/10.1007/s11356-019-04793-Z

Qian Y, Song KH, Hu T, Ying TY (2018) Environmental status of livestock and poultry sectors in China under current transformation stage. Sci Total Environ 622:702-709. https://doi.org/10.1016/j.scitotenv.2017.12.045.

Qin GB (2019) problems and feeding management of perinatal dairy cows. Mod. Anim. Husb. Tech. 12:34-35 (In Chinese)

Reza B, Sadiq R, Hewage K (2014) Emergy-based life cycle assessment (Em-LCA) for sustai nability appraisal of infrastructure systems: a case study on paved roads. Clean Tech. Env iron. Polic. 16:251-266. https://doi.org/10.1007/s10098-013-0615-5.

SCA (Standardization Administration of the People's Republic of China) (2012) Ambient ai r quality standards (GB 3095-2012). http://www.sac.gov.cn/gzfw/ggcx/gjbzgg/201213/. Acc essed 28 October 2020.

SCA (Standardization Administration of the People's Republic of China) (2017) Quality sta ndard for ground water (GB/T 14848-2017). http://www.sac.gov.cn/gzfw/ggcx/gjbzgg/201 726/. Accessed 28 October 2020.

Ulgiati S, Brown MT (2002) Quantifying the environmental support for dilution and abatement of process emissions - The case of electricity production. J Clean Prod 10:335-348. https://doi.org/10.1016/S0959-6526(01)00044-0.

Wang L, Li L, Cheng K, Ji C, Yue Q, Bian R Pan G (2018) An assessment of emergy, energy, and cost-benefits of grain production over 6 years following a biochar amendment in a rice paddy from China. Environ Sci Pollut Res 25:9683-9696.

Wang QS, Xiao HK, Ma Q, Yuan XL, Zuo J, Zhang J, Wang SG Wang MS, 2020 Review of Emergy Analysis and Life Cycle Assessment: Coupling Development Perspective. Sustainability. 12:367. https://doi.org/10.3390/su12010367.

Wang XL, Dadouma A, Chen YQ, Sui P, Gao WS, Jia LH (2015) Sustainability evaluation o $\mathrm{f}$ the large-scale pig farming system in North China: an emergy analysis based on life cy cle assessment. J Clean Prod 102:144-164. https://doi.org/10.1016/j.jclepro.2015.04.071.

Wesseh PK, Lin B, (2017) Options for mitigating the adverse effects of fossil fuel subsidies removal in Ghana. J Clean Prod 141:1445-1453. https://doi.org/10.1016/j.jclepro.2016.09.2 
14.

Wilfart A, Prudhomme J, Blancheton J, Aubin J (2013) LCA and emergy accounting of aquaculture systems: Towards ecological intensification. J Environ Manage 121:96-109. https://doi.org/10.1016/j.jenvman.2013.01.031.

Wu XH, Wu FQ, Tong XG, Wu J, Sun L, Peng XY (2015) Emergy and greenhouse gas assessment of a sustainable, integrated agricultural model (SIAM) for plant, animal and biogas production: Analysis of the ecological recycle of wastes. Resour Conserv Recycl 96:40-50. https://doi.org/10.1016/j.resconrec.2015.01.010.

Wu XH, Wu FQ, Tong XG, Jiang B (2013) Emergy-based sustainability assessment of an integrated production system of cattle, biogas, and greenhouse vegetables: Insight into the comprehensive utilization of wastes on a large-scale farm in Northwest China. Ecol Eng 61:335-344. https://doi.org/10.1016/j.ecoleng.2013.09.060.

Yang L, Wang CD, Yu HJ, Yang MJ, Wang SB, Chiu ASF, Wang YT (2020) Can an island economy be more sustainable? a comparative study of indonesia, malaysia, and the philip pines. J Clean Prod 242:118572.1-118572.9. https://doi.org/10.1016/j.jclepro.2019.118572.

Yang ZF, Jiang MM, Chen B, Zhou JB, Chen GQ, Li SC (2010) Solar emergy evaluation fo r Chinese economy. Energy Policy. 38:875-886. https://doi.org/10.1016/j.enpol.2009.10.03 $\underline{8}$.

Yang ZX, Gao Y, Zhao ZQ, Li SC (2012) Research on three small-scale agricultural ecological-economic systems in Shenzhen City based on emergy analysis. Acta Ecol Sinica 32: 3635-3644 (In Chinese)

Yuan J (2019) aquaculture reform in the era of Internet of things. Anim. Husb. Vet Med Today 35 (03):57 (In Chinese)

Zhang H, Keoleian GA, Lepech MD, Kendall A (2010) Life-Cycle Optimization of Pavement Overlay Systems. J Infrastruct Syst 16:310-322. https://doi.org/10.1061/(ASCE)IS.1943-55 $\underline{5 X .0000042 .}$.

Zhang LX, Song B, Chen B (2012a) Emergy-based analysis of four farming systems: insight into agricultural diversification in rural China. J Clean Prod 28:33-44. https://doi.org/10.10 16/j.jclepro.2011.10.042.

Zhang S, Bi XT, Clift R (2015) Life cycle analysis of a biogas-centred integrated dairy farm-greenhouse system in British Columbia. Process Saf. Environ Protect 93:18-30. https://doi.org/10.1016/j.psep.2014.02.017.

Zhang XH, Wei Y, Li M, Deng SH, Wu J, Zhang YZ, Xiao H (2014) Emergy evaluation of an integrated livestock wastewater treatment system. Resour. Conserv. Recycl. 92:95-107. https://doi.org/10.1016/j.resconrec.2014.09.003. 
598 Zhang XQ, Huang GQ, Bian XM, Jiang XH, Zhao QG (2012b) Effects of intercropping on quality 599 and yield of maize grain,microorganism quantity,and enzyme activities in soils. Acta Ecol $600 \quad$ Sinica 32:7082-7090 (In Chinese)

601 Zhao CG 2020 Common feed and preparation methods for dairy cattle. Feed Expo 6:77 (In Chinese) 
Figures

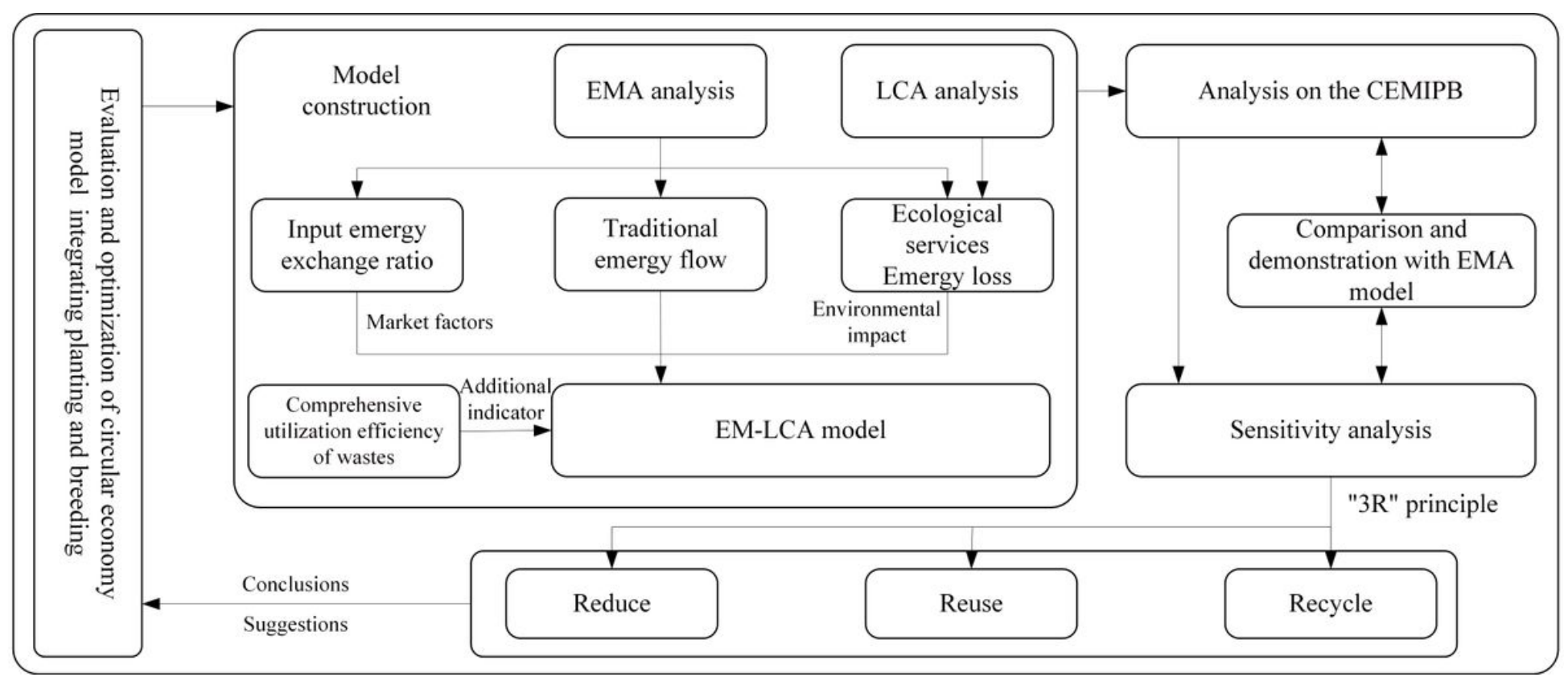

Figure 1

Roadmap of research methodology for CEMIPB

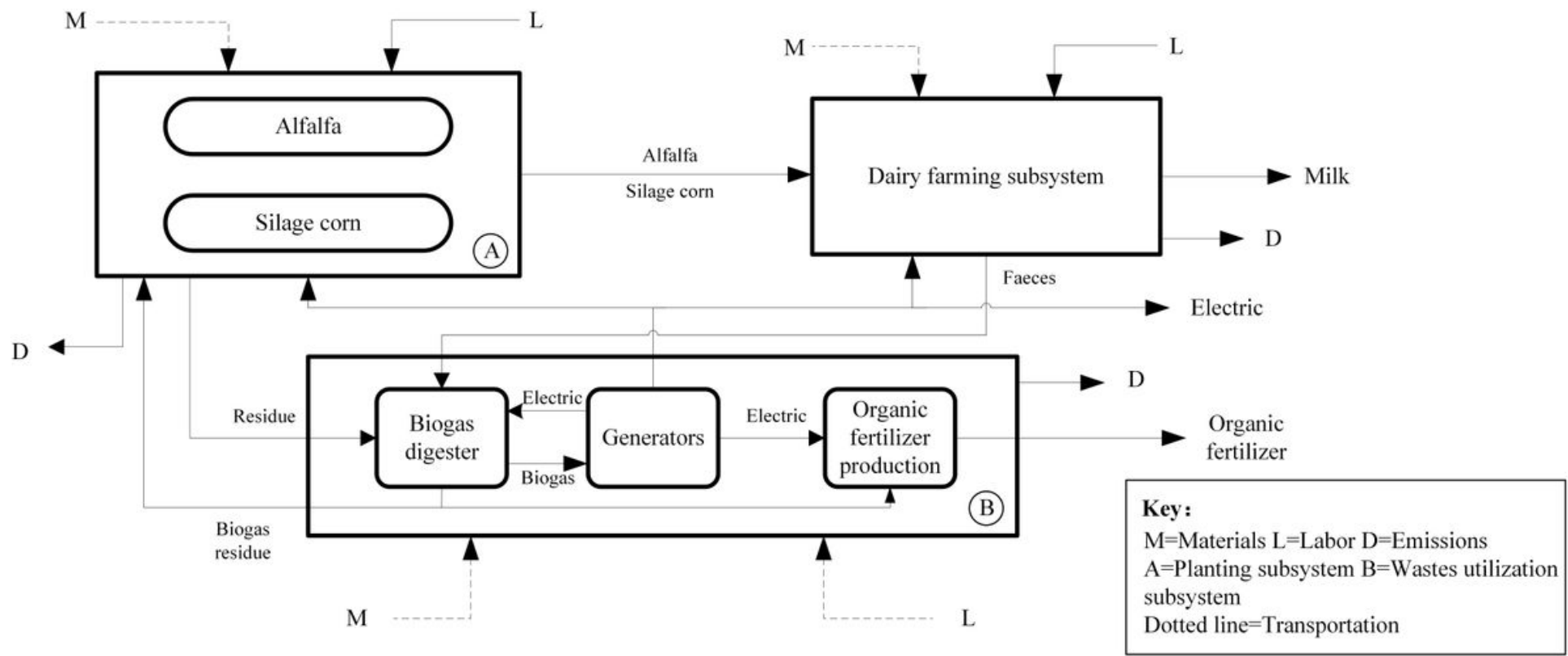

Figure 2

Flow chart of the CEMIPB 


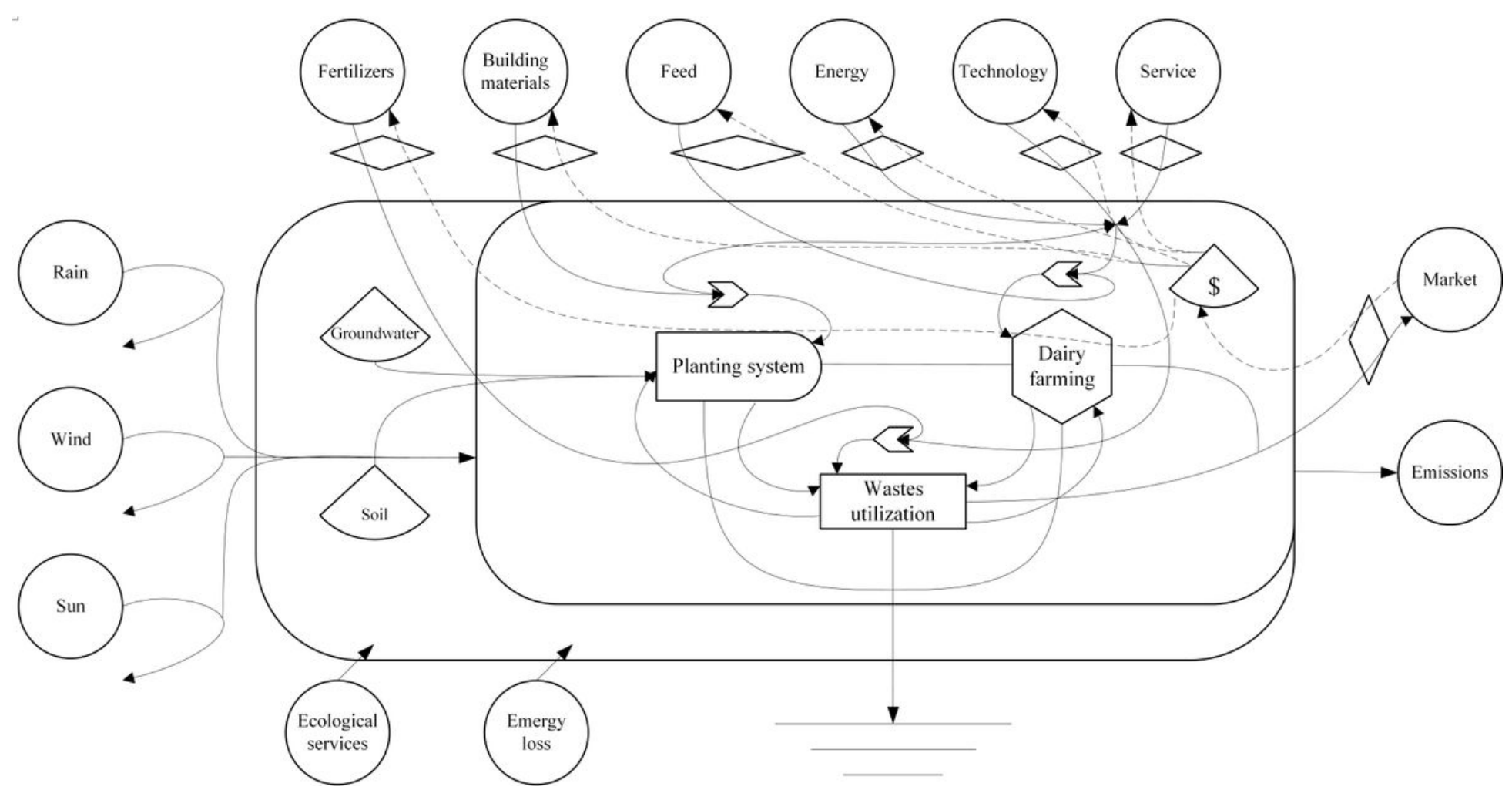

Figure 3

Emergy flow chart of the CEMIPB

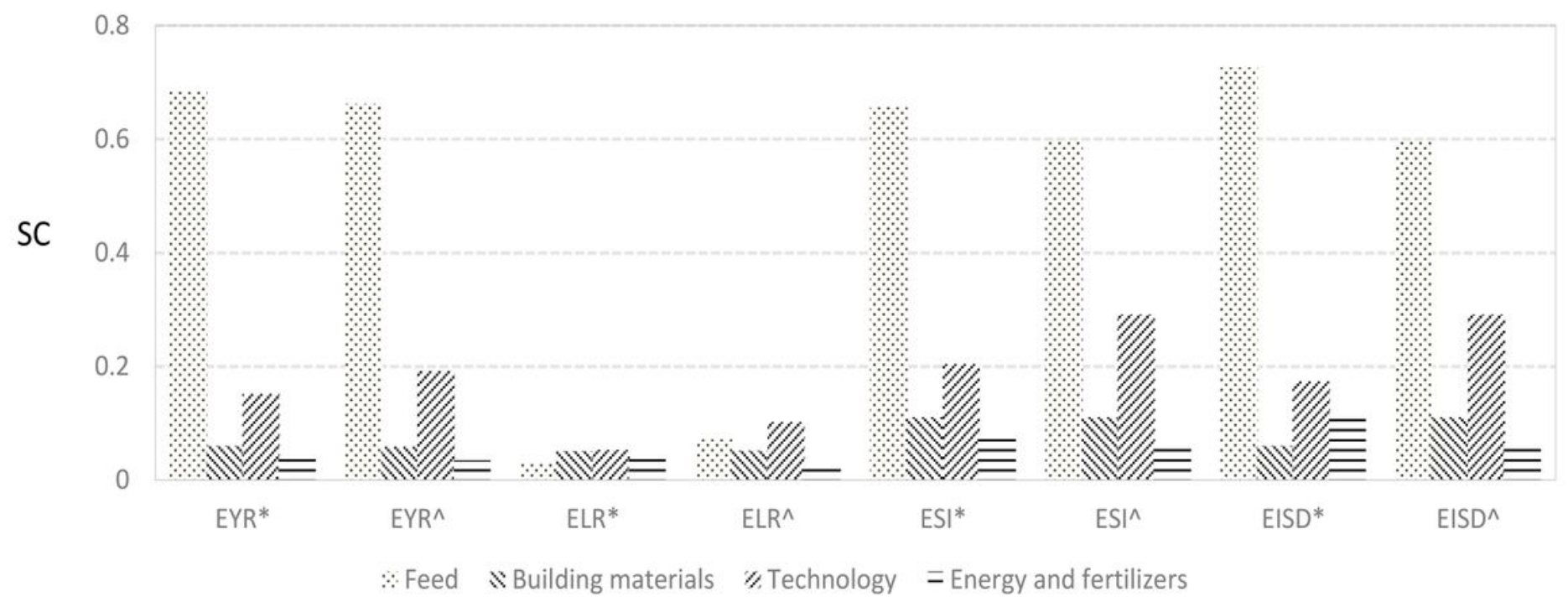

Figure 4

Impact of $10 \%$ emergy flow increase on key indicators (* represents the EM-LCA model; ^ represents the EMA model) 


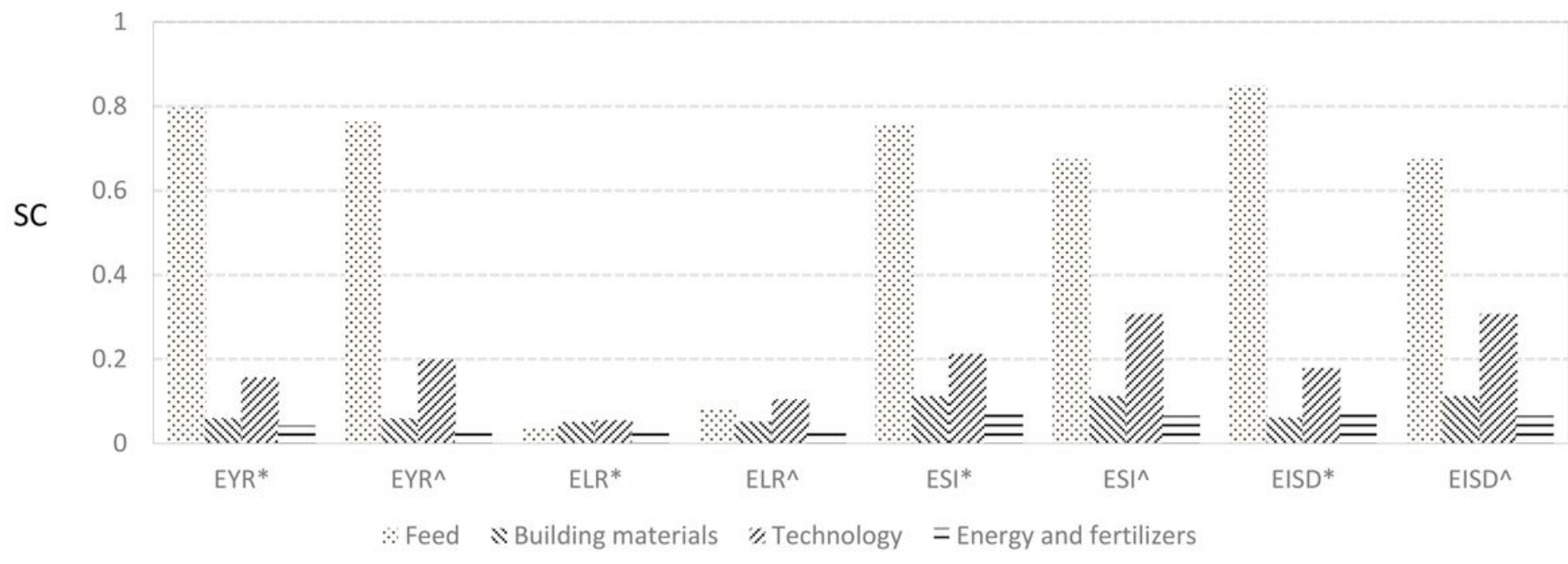

Figure 5

Impact of $10 \%$ emergy flow decrease on key indicators (* represents the EM-LCA model; ^ represents the EMA model) 